\title{
Ney Messias e o ensino do processo penal ${ }^{*}$
}

\author{
Plinio de Oliveira Corrêa ${ }^{\star \star}$
}

Em 1932, o professor Ney Messias escreveu um poema, donde se destaca esta passagem:

Quando a cadencia de meu passo incerto

Passar no último pouso da existência; Quando eu sentir morrer minha consciência

Como um grito perdido no deserto;

Quando eu for qual átomo esquecido Na profundeza caótica do nada,

Não haverá sinal de mim na estrada

Porque eu passei sem ser apercebido.

Felizmente, enganou-se o ilustre professor ao fazer essa previsão, quando tinha apenas 19 anos de idade. Senão vejamos:
Os bacharéis de 1969 imprimiram para sempre no bronze de uma placa fixada no saguão desta Casa, esta homenagem ao seu paraninfo:

E quando ele se calou, nosso coração continuou a ouvir [...]

Daí em diante seguiram-se incontáveis louvores, seja do Poder Público, designando o seu nome para uma rua desta Capital; sejam as publicações jurídicas que lhe foram dedicadas, como A Provocação Jurisdicional e a Legitimidade da Prisão no Direito Brasileiro; seja a edição póstuma de sua obra literária $O$ Construtor de Mistérios; seja a

* Ney Messias e o Ensino do Processo Penal foi o tema abordado pelo prof. Plínio de Oliveira Corrêa, em 21.06.99, no Ciclo de Conferências sobre a "Influência da Faculdade de Direito da UFRGS na Política e nas Letras Jurídicas", que a Gestão do Centenário da "Casa de Thompson Flores e André da Rocha" promoveu no período de 05.04.99 a 19.07.99, tendo por local o Salão Nobre da Faculdade de Direito.

** Professor adjunto e diretor da Faculdade de Direito da UFRGS, gestão 2000/04. 
transferência das distinções de paraninfo à sua memória $\left(80^{\mathrm{a}}\right.$ Turma de Bacharéis em Direito da UFRGS); sejam os inúmeros artigos e reportagens de juristas, de políticos, de jornalistas e de literatos, todos enaltecendo suas virtudes e suas qualidades, como nestes depoimentos:

- Do poeta Mário Quintana:

Ney Messias foi um homem de luta e de sonhos na tentativa de salvar o mundo. Ele rejuvenescia a gente.

- Do jornalista Janer Cristaldo:

De certa forma, agradeço não ter tido a oportunidade de conhecê-lo pessoalmente. De longe, vislumbro melhor sua grandeza. Estamos diante de um homem da estirpe de Nietzsche e de Pessoa. Eestes seres, por discretos que pretendam ser, não conseguem passar desapercebidos.

- Do jurista Paulo Brossard:

O Ney não tinha talento, tinha talentos, e em tudo era eximio e original, ainda que nenhuma preocupação tivesse em sê-lo; havia coisas que só ele era capaz de dizer ou de fazer, coisas que a ninguém poderiam ocorrer, nele brotavam com a espontaneidade do dia que nasce. Não havia outro Ney. Ney era um só.

Por isto mesmo aqueles que não o conheceram não podem ter idéia do homem que deixaram de conhecer. Por muitos que fossem os seus talentos, $o$ homem ainda era melhor. Terno como uma criança, bravo até a temeridade, generoso, compreensivo, era a correção em pessoa. Leal, franco, bom. As suas qualidades de coração e de caráter eram tão vivas, que eu chego a esquecer- me das cintilações da sua inteligência. Todos os dias, à hora certa, estávamos juntos e fruíamos o Ney - o Ney das crônicas, o Ney poeta, o Ney professor, o Ney galhofeiro, o Ney humorista, o Ney cavalheiro. Certo dia, depois de anos de convívio diário ele se foi. Ficamos todos engasgados. Mas continuamos a falar nele, porque ele continuava conosco.

- E, Mário de Almeida Lima, o sintetizou nesta parábola:

O Ney era tão genial que seria capaz de abraçar a Torre Eiffel e trazê-la para o Brasil, dando em troca apenas uma estatueta de canela de burro, por ele esculpida, acomodando a ira do general De Gaulle.

E neste momento solene anunciamos, para breve, mais uma publicação em sua homenagem, que vai conservar viva sua lembrança para o próximo milênio: Ação Penal Originária - Procedimentos, que já circula de forma incipiente junto à PósGraduação em Ciências Penais.

Esse curso, a propósito, houve por bem instituir no seu Regimento o que segue (artigo 79):

[...] será conferida a Medalha Professor Ney Messias ao docente que tiver destacada atuação no Curso de Especialização em Ciências Penais e demonstrar excepcional dedicação ao estudo e à pesquisa no campo das ciências criminais.

E, em 1995, o docente que primeiro recebeu este título, por decisão 
unânime dos especializandos, registrou esta dedicatória em edição especial de obra que publicara:

Dedicamos este livro à $1^{a}$ turma do Curso de Especialização em Ciências Penais da Faculdade de Direito da Universidade Federal do Rio Grande do Sul, agradecendo a homenagem contida na outorga da Medalha Professor Ney Messias, cuja honra estamos repartindo com os demais professores do curso.

E a parte que nos toca nesta divisão, desejamos transferir à memória do imortal Jurista que dignificou a Cultura, o Magistério e as Letras Jurídicas - o próprio professor Ney Messias.

Anteriormente, a turma de 1965 já o escolhera como paraninfo, cuja solenidade de formatura marcou época pelos corajosos pronunciamentos em favor do Estado de Direito e da Ordem Democrática, incluindo o significado político do lema: Cedam as Armas à Toga.

Agora, passados quase trinta anos do seu falecimento, os nossos corações continuam a ouvi-lo [...], pois espíritos especiais e privilegiados não passam desapercebidos pela estrada da vida, e seu exemplo e seus ensinamentos costumam se perpetuar, estendendo-se para muito além do horizonte do tempo...

E dentre os nomes ilustres que fizeram a história deste templo, onde se ministra o Evangelho do Direito, o de Ney Messias é, certamente, o mais fácil e o mais difícil de se discorrer. Sua personalidade foi tão marcante e tão retilínea, tão límpida e tão transparente, tão humana e tão cativante, tão rica e tão múltipla em profundidade e extensão cultural que, se de um lado facilita, de outro dificulta ao expositor.

Essa foi a explicação dada por diversos convidados, que agradecendo ao honroso convite, alegaram a impossibilidade de tratar dos inúmeros "Neys" em tão curto espaço de tempo.

Então - e por exclusão - é que esta "missão impossível" coube a quem apenas teve o privilégio de ter sido seu discípulo, seu paraninfado, seu amigo pessoal, seu colega de escritório, seu assistente na cátedra e modesto continuador de suas brilhantes aulas de processo penal.

E mesmo diante das dificuldades apontadas, vamos iniciar dizendo que o nosso homenageado nasceu a 24 de setembro de 1913, em São João Baptista do Quarahy, neste Estado; viveu em Uruguaiana, Santa Maria e Porto Alegre, onde faleceu em 23 de janeiro de 1970. Foi casado com Dona Ondina Dornelles Messias, de cuja união resultou o nascimento de dois filhos: Sérgio Dornelles Messias, conceituado médico psicanalista, e Gladys Messias de Figueiredo, dedicada professora de Letras; Bacharelou-se em Direito e Filosofia por esta Universidade; cursou a Escola Superior de Guerra no Rio de Janeiro; foi advogado militante; escritor exímio; jornalista atuante e diretor de jornal; chefe do departamento jurídico do Clube, que mais venceu gre-nais e que mais conquistou campeonatos gaúchos de futebol; membro do 
Conselho Penitenciário do Estado; procurador do Estado do Rio Grande do Sul; primeiro diretor da Caixa de Assistência da Ordem dos Advogados do Brasil, neste Estado; professor catedrático de Direito Processual Penal nesta Faculdade, onde exerceu o magistério jurídico no período de 31 de março de 1951 a 23 de janeiro de 1970.

Além de penetrar pelos largos horizontes do Direito e da Filosofia, fez estudos de Sociologia e de Política, de Psicologia e de Psicanálise, de Astronomia, de Astrologia e das Ciências Holísticas, atualmente tão difundidas pela globalização e no âmbito da paranormalidade. Também não ficou indiferente à pintura, à composição, à arte $\mathrm{e}$ à escultura, tendo deixado trabalhos memoráveis. Enfim, brilhou em tudo e encantou a todos, esbanjando talentos, humanismo e lições de ética em cada uma dessas áreas do conhecimento.

Mas foi, sobretudo, um político de escol, que criticava construtivamente os políticos, especialmente aqueles, cujos partidos, vencendo ou perdendo as eleições, estavam sempre no poder; foi um cidadão ativo e atuante, que exerceu a cidadania em sua plenitude, não hesitando jamais em se opor à prepotência dos poderosos, resistindo ao império das leis injustas, dos seus intérpretes e aplicadores; enfim, foi um advogado modelar e um professor sábio e independente, que assumia posições corajosas, visando o aperfeiçoamento da Ordem Jurídica, como instrumento para atingir o Bem Comum, esse Bem
Comum, assim concebido por João XXIII e pelo nosso professor Câmara: - o primeiro, o definia como o conjunto de condições sociais que possibilitam e favorecem o desenvolvimento integral da personalidade; e o segundo, o conceituava como o conjunto de situações ou condições de vida, individual e social, que assegura a realização dos fins humanos.

Mas, retomando o tema pontual deste evento, cabe acentuar que desde a sua criação até 1963 , o curso de bacharelado desta Faculdade teve apenas uma única cadeira de Processo Penal, a qual, na época, estivera sob a responsabilidade docente do professor Francisco José Simch Júnior. A partir daí foi instituída a segunda Cadeira desta disciplina, que ficou sob a regência e titularidade do nosso homenageado, que até então era assistente do prof. Simch.

Qual foi, então, o perfil dado pelo professor Messias ao ensino do Processo Penal, aqui ministrado?

A par das Lições de Processo Penal, condensadas neste volume único que estamos destinando à nossa Biblioteca, e que representam o resgate de uma parte de suas aulas, - desejamos destacar, neste momento, outras notas doutrinárias e complementares, assim resumidas:

\section{O ensino analítico, sistema- tizado e comparativo}

Cabe referir, desde logo, a projeção metodológica encetada pelo mestre, 
que, inovando os métodos tradicionais, não se fixava apenas neste ou naquele tema, isoladamente, mas sim de forma dinâmica, comparativa e globalizante.

Assim, como que adotando a filosofia orteguiana, partia do essencial e magistralmente enveredava por todas as circunstâncias pontuais, relacionando a matéria, comparativamente, com as demais províncias do ordenamento jurídico.

Em outras palavras, partia dos institutos consagrados pelo Direito Positivo e ia sistematizando o estudo do Processo Penal com os demais ramos não só da Teoria Geral do Processo, mas também da Teoria Geral do Direito e, ainda, correlacionando com as conquistas inseridas nas declarações de direitos das diferentes épocas, bem como conjugando as últimas conclusões dos conclaves jurídicos nacionais e as recomendações doutrinárias dos congressos internacionais da ciência do Direito.

E não parava aí, prosseguia na análise interligando a abordagem didática da matéria com as outras ciências afins, circunscritas ao seu objeto finalístico: o ser humano, situado não num mundo imaginário e ilusório, mas plantado na concretude das relações interpessoais e devidamente sintonizado com a realidade e com o convívio no meio ambiente.

Examinava a crise do Judiciário e, particularmente, do processo penal, como resultante do processo social em crise, sendo oportuno recordar esta passagem:
É assim, no processo de desidentificação social, que o estudante se transforma em operário, que o sacerdote vira guerrilheiro, que o filósofo vem a ser pregador de comicios, que o militar invade a área civil, que o artista, à força de buscar em si o outro, transfigura-se no agente publicitário da indústria com a sua incrivel pop-arte. Dai para as deformações da cultura, da pintura, da poesia, do direito, do magistério, da magistratura, dafilosofia e do bom senso, o passo é curto, dolorosamente curto. Confuisão total, guerra total, desajustamento total.

Com esta metodologia, procurava buscar não só a ontologia da norma, mas a sua deontologia jurídica para que o intérprete pudesse apreender o seu espírito e projetar a sua correta interpretação no tempo e no espaço.

Este estilo inovador de ensinar e de se fazer entender, que só ele conseguiu imprimir nesta Casa, era fruto de sua privilegiada inteligência e de seu sólido e profundo preparo cultural, dominando vários ramos das Ciências Humanas e fazendo com que todos ficassem como que hipnotizados com o legado de suas exposições, que, ao final, culminavam, muitas vezes, em aplausos prolongados para um novo e sempre esperado recomeçar...

\section{A provocação jurisdicional}

Quando, em suas aulas, tratava dos Sistemas Processuais - que são as grandes avenidas pelas quais passa e 
se define a filosofia do processo - o professor se posicionava pelo Sistema Acusatório, em franca oposição ao Sistema Inquisitório.

Com efeito, dentro dessa orientação doutrinária, ao elencar os postulados informadores do processo penal, destacava o princípio da provocação jurisdicional, pelo qual o juiz somente pode agir se for provocado e, ainda, nos limites da imputação e do pedido, evitando, desta forma, decisão ultra, citra e extra petita. Com isto preservava a imparcialidade do magistrado, assim concebida por Bettiol:

A história do processo penal é a história de uma luta orientada para a conquista de um juiz imparcial, que atua a nivel distinto e superior ao das partes.

E, quando analisava, por exemplo, o conteúdo dos artigos 26 e 531 do Código de Processo Penal, bem como da Lei N. $.^{\circ} 4.611 / 65$, que, nos casos de contravenção penal, lesão corporal culposa e homicídio culposo, permitiam ao juiz instaurar o processo - acusando e julgando ao mesmo tempo - o nosso Ney foi, certamente, a voz que primeiro levantou apontando a incongruência desta posição, diante dos ensinamentos doutrinários, especialmente, de Búlgaro e de Büllow, que consideravam o processo como actus trium personarum: o autor que acusa, o réu que se defende e o juiz que julga.

Além desta direta permissibilidade legal ex-officio, o nosso Código ainda permite que, indiretamente, o juiz tome a iniciativa acusatória, como se constata pelos preceitos dos artigos $28,383,384$ e $\S$ único, e $408 \S \S 4^{\circ}$ e $5^{\circ}$, do aludido diploma.

Todos estes dispositivos legais, que ainda hoje integram o nosso código, representam um retrocesso ao odioso inquisitorialismo, onde o acusado só tem o direito de não ter direito algum.

E suavizava a crítica, com estas palavras:

No processo jurisdicional é indispensável a divisão de tarefas. Um é o que acusa, outro éo que defende, e um terceiro é o que julga, isso para não aludir às tarefas complementares como a do perito. Não pode o juiz acusar, nem élicito ao acusador defender, enquanto o patrocínio da defesa impede, obviamente, que o defensor acuse. Técnica, ética e logicamente, o processo se desenvolve através da especialização de funções, ou mediante a fidelidade dos agentes à tarefa que se propõem exercer. Em suma, no processo cada um é o que é: princípio de identidade que não pode ser desatendido sem que se torne perigosa e instável a ordem processual.

E, ao finalizar, invocava este histórico preceito do artigo 110 do Código de Processo Penal do Rio Grande do Sul:

Os (juizes e os) tribunais não podem ex-officio promover a ação penal.

No âmbito do Direito Comparado, tanto interno quanto externo, este diploma rio-grandense é 
o único que consagra claramente o princípio da provocação jurisdicional e que, somente agora, a Constituinte de 1988 instituiu o preceito do artigo 129, inciso I, da nossa lei maior, que sepultou, definitivamente, o inquisitorialismo judiciário no sistema processual penal brasileiro.

\section{Postulação por um código votado pelo poder legislativo e a crítica ao anteprojeto Tornaghi}

Dentre muitas preocupações do mestre com o ensino do Processo Penal, cabe destacar o fato de que até então (e continua) não possuíamos um Código de Processo Penal que tivesse passado pelo Poder Legislativo.

Todos os diplomas resultaram de ato exclusivo do Poder Executivo. Foi assim com o Código de Processo Criminal de 1832, bem como com as reformas de 1841 e de 1871. Com o advento da Constituição de 1891, se implantou no país o princípio da descentralização processual, permitindo que os Estados legislassem sobre Direito Processual. E o Rio Grande do Sul foi o Estado que promulgou o $1^{\circ}$ Código Estadual de Processo Penal, em 1898, seguindo-se, em regra, os demais Estados da Federação.

Com a Revolução de 1930 adveio a Constituição de 1934, que restabeleceu o princípio da unidade processual, concentrando na União, como ocorre até hoje, o poder de legislar sobre Direito Processual.

Assim, em 1941, foi promulgado pelo Poder Executivo o atual Código de
Processo Penal. Três anos antes, em 1938, foi editado o Código de Justiça Militar, revogado, em 1969, pelo vigente Código de Processo Penal Militar, instituído pelos três ministros militares, da época, que assumiram o poder central face a enfermidade do presidente Costa e Silva, e o fizeram, ainda, com base nos atos institucionais $n .^{\circ} 5$ e $n^{\circ} 16$.

Tal situação sempre mereceu as mais acirradas críticas do professor Messias, que defendia uma reforma sistematizada do nosso atual diploma, mas através do Poder Legislativo e mediante o encaminhamento ao Congresso $\mathrm{Na}$ cional de um projeto de lei que consultasse as aspirações do mundo jurídico e atendesse à evolução científica do Direito Processual.

Por solicitação do sr. João Mangabeira, ministro da Justiça, veio, então, em 1963, o anteprojeto de código elaborado pelo professor Hélio Bastos Tornaghi que, inobstante a autoridade e o renome do seu autor, pecava por excesso de conceitos e definições dos institutos, esquecendo que tal mister deveria ser obra da doutrina e não de um código, destinado a regular objetivamente as inúmeras e complexas situações jurídicas dentro do processo.

Este pecado original - conceitualismo e excesso de definições - logo foi percebido e apontado pela crítica aguda do nosso professor, cabendo ressaltar, entre tantos outros, os seguintes dispositivos do anteprojeto:

- O artigo 43, dava a definição oficial de relação processual; 
- $O$ artigo 82, definia o que se deveria entender por pressupostos processuais;

- Os artigos 177 a 183 e 196, conceituavam fato, ato e negócio processual, bem como ato discricionário e ilegalidade;

- Os artigos 300 e 308 , apresentavam uma noção do que se deveria entender por documento e indícios. $\mathrm{E}$ assim por diante.

Esta crítica procedente ao anteprojeto Tornaghi generalizou-se, e após 1964 foi definitivamente afastado pelo regime autoritário, sendo substituído pelo anteprojeto do professor José Frederico Marques, que, depois de revisado, foi encaminhado primeiramente à Câmara dos Deputados e transformado no Projeto de Lei N $.^{\circ} 633 / 75$.

Este projeto, após receber emendas e sugestões do mundo jurídico brasileiro, foi aprovado por unanimidade na Câmara dos Deputados e, quando já tramitava no Senado Federal sob o $n .^{\circ}$ $05 / 78$, foi retirado, inexplicavelmente, pelo Poder Executivo para estudo, e continua até hoje sendo estudado pelo esquecimento oficial.

Seguindo a mesma orientação do Projeto N. ${ }^{\circ} 633$, em 1979 o deputado Sérgio Murilo, que havia presidido a Comissão Especial que estudou o preterido projeto, o reapresentou sob N ${ }^{\circ}$ 1.268 , mas o mesmo foi arquivado na legislatura seguinte.

Em 1983, através da Mensagem Presidencial N. ${ }^{\circ} 241$, o Governo encaminhou outro projeto de código, conservando as linhas mestras dos dois projetos originais, que tomou o N. ${ }^{\circ} 1.655$, sendo abandonado mais uma vez.

Em 1994 o Poder Executivo ensaiou outra tentativa, remetendo ao Congresso Nacional um pacote de 17 projetos, visando a reformas parciais do atual código que, transcorrido algum tempo e com exceção de um deles, também foram relegados por inconstitucionais, naquilo que o próprio Governo alterou da proposta elaborada por uma comissão de juristas.

E assim é que continuamos com o vetusto e cada vez mais assistemático Código, editado pelo Poder Executivo há mais de meio século, sem que fosse ouvida a postulação do professor Messias, bradando por uma lei processual penal que resultasse do óbvio, isto é, uma lei votada pelo Poder Legislativo.

Neste particular, a indevida intromissão do Executivo e a inexplicável omissão do Legislativo, têm sido agravadas pela indiferença da doutrina, retratada nesta constatação de Carnelutti, lembrada, aliás, nas lições do nosso homenageado:

Era uma vez três irmãs que tinham em comum, pelo menos, um de seus progenitores: chamavam-se ciência do direito penal, ciência do processo penal e ciência do processo civil. Ocorreu que a segunda, em comparação com as outras duas, que eram mais belas e prósperas, teve uma infância e uma adolescência infelizes. Com a ciência do direito penal coubelhe dividir durante muito tempo a mesma habitação; e aquela reteve para si o bom e o melhor.. 
Com a ciência do processo civil tem ocorrido situação semelhante, uma vez que noventa por cento do progresso do processo penal é mera adaptação do processo civil, (devido ao comodismo dos processualistas penais)...

Enfim (é doloroso reconhecer que) a ciência do processo penal, isto é, a nossa Cinderela, tem se contentado com os vestidos jogados fora por suas irmãs mais afortunadas...

Por isso, a geração que hoje é responsável pelos destinos desta Faculdade centenária, vai implementar as idéias do professor Ney Messias - concentrando-as num novo anteprojeto a ser elaborado juntamente com os órgãos representativos da Sociedade Jurídica Rio-grandense-Ordem dos Advogados, Instituto dos Advogados, Associações dos Juízes, do Ministério Público, dos Defensores Públicos e dos Delegados de Polícia-e, depois, encaminhá-lo ao Poder Legislativo Federal através do concurso de todos os componentes da bancada gaúcha no Congresso Nacional.

Oxalá possamos contar, brevemente, com um Código de Processo Penal que não só seja votado pelo Poder Legislativo, mas também satisfaça às aspirações e aos anseios da comunidade jurídica brasileira, como desejava o nosso ilustre homenageado.

\section{Teoria da ação penal}

Outra significativa contribuição do professor Messias diz respeito à teoria da ação e, particularmente, à ação penal, publicando, em 1951, estudo coincidente com as conclusões aceitas pela doutrina contemporânea.

Com efeito, ao que se sabe foi o jurisconsulto Celso, no Digesto (D. $44,7,51)$ e nas Institutas (I. 14,6, $2^{\mathrm{a}}$ parte), quem primeiro definiu a ação como o direito de exigir em juízo aquilo que lhe é devido (actio nihil aliud est quam jus persequendi in judicio quod sibi debetur).

Por mais de quatorze séculos o tema ficou intocável, como um dogma indiscutível e indiscutido.

No fim da Idade Média, porém, o jurista Hottomamus pretendeu acrescentar ao texto uma pequena glosa; o mesmo aconteceu com Savigny, no século passado. Embora estas tentativas não tivessem logrado êxito, a preocupação destes autores serviu para despertar a discussão dos estudiosos da Ciência do Direito, cabendo referir a célebre polêmica entre Windscheid e Muther a respeito da actio romana, em meados do século passado, que trouxe importante contribuição para a independência do Direito Processual. Na mesma época e nesta direção, merece registro a contribuição do professor recifense Francisco de Paula Batista.

A partir daí foram surgindo novas teorias à margem da milenar concepção civilista, como: a do direito concreto de agir, de Wach; a do direito potestativo, de Chiovenda; a do direito abstrato, de Degenkolb e Plósz; a eclética, do nosso professor Galeno; a do direito cívico constitucional, de Couture; e a das 
condições da ação civil, referidas por Chiovenda, mas adaptadas magistralmente por Liebman.

Pois bem, neste conflito doutrinário sobre a natureza jurídica da ação, o professor Messias, simplificando toda essa infindável discussão, publicou, há meio século, um estudo intitulado Direito subjetivo e conceito da ação penal, concluindo que a ação nada mais era do que o direito à provocação jurisdicional, isto é, o direito subjetivo à prestação judicial pela sentença, que, só recentemente, a evolução científica do Direito Processual chegou ao mesmo entendimento.

Graças à orientação do mestre, desenvolvemos estudo complementar sobre a teoria da ação penal, mais propriamente a respeito de sua qualificação distintiva, isto é, as condições para o seu exercício, divididas, sistematicamente, em condições gerais, especiais e formais.

\section{Constituição dos tribunais}

A mesma isenção que deve informar o objeto interno do processo, na investigação do tema penal, deve orientar externa e institucionalmente a constituição dos órgãos jurisdicionais, na distribuição da Justiça, sejam eles juízos monocráticos, sejam eles juízos colegiados, pois, como ensinava o prof. Messias:

O interesse interno ao objeto principal do processo é tipicamente parcial. É calorosamente parcial. Parcial é a acusação; parcial é a defesa. E a imparcialidade do juiz, esta postura de eqüidistância, é algo absolutamente necessário para que, das parcialidades da acusação e da defesa, vença aquela que está marcada por um interesse legitimo. Isto é fazer justiça segundo uma programação oficial, segundo um desejo, uma opção especialíssima do grupo social, revelada na legislação. Um juiz pode ser sábio, mas se ele, ainda que remotamente, tiver determinados interesses coincidentes com os interesses que estão discutindo, ele corre o risco da parcialidade.

No que diz respeito à constituição dos membros integrantes dos nossos tribunais, o professor defendia a tese que deveria obedecer à seguinte composição:

- 1/3 dos juízes, advindo da magistratura, - 1/3, provindo do Ministério Público,

$-1 / 3$, indicado pela Ordem dos Advogados.

Tal constituição deveria resultar da escolha exclusiva dos três órgãos representativos, sem qualquer interferência política, que lhe retira a independência e restringe a confiança dos jurisdicionados.

Com esta composição de pesos e contrapesos, certamente, acabaria não só com o polêmico controle da Magistratura, mas com os apadrinhamentos político-partidários, numa escandalosa deturpação da filosofia franciscana do é dando que se recebe.

\section{Teleologia do processo}

Outra questão doutrinária interessante, levantada pelo mestre, consiste na indagação teleológica do processo. 
É evidente - ensinava - que encon-tramos no processo fins múltiplos e, conseqüentemente, resultados múltiplos, desde que plural é o seu objeto: a cada objeto corresponde um fim especifico; cada objeto, de sua vez, chegará ao resultado correspondente.

Cabe observar - continuava - que a atividade processual, como obra humana, corre o risco de não atingir a sua finalidade substancial. Tal risco é conseqüente, primeiro, da própria imperfeição do trabalho humano. Convém atentar para o fato de que o processo é uma técnica de investigação usada por sujeitos que, embora todos os graus de especialização de que são por-tadores, não podem atingir o ideal de perfeição. Assim, a imperfeição do sujeito se manifesta na imperfeição da técnica, que é inseparável do sujeito.

Além disso, a técnica do processo está juridicamente limitada por princípios de respeito à dignidade humana. A coação fisica pela dor, a coação moral pelas ameaças e pelo medo, os métodos científicos de inspeção psicológica ou psico-biológica (tais os aventados pela aplicação do detector de mentiras, a ministração de drogas como a escopolamina, o emprego de artificios na devassa do foro intimo como a hipnose e outras formas de catarsis psicológica) são meios de investigação $e$ de apuração da verdade processual como técnicas inaceitáveis e imorais. Com todas essas limitações, a técnica de investigação processual corre o risco do erro, que a lei procura conjurar mediante a possibilidade de reexame da decisão pelo recurso a um juizo de segundo grau e, até mesmo, pela revisão criminal.

Resta claro, agora, o motivo pelo qual se fala em fim e em resultado do processo.
A diferença, pois, entre fim e resultado está na distância que existe entre o ideal e a possibilidade de atingi-lo.

Com efeito, quando todos pareciam satisfeitos com a resposta de que o fim do processo é a sentença justa, o nosso professor aprofundou a análise, destacando que, no caso, havia necessidade de se distinguir, de um lado, a teleologia do processo e, de outro, a axiologia da jurisdição. E dizia - a jurisdição tem por finalidade a sentença justa, ou seja, a sentença justa é o fim do Poder Jurisdicional.

Agora, se a jurisdição é exercida através do processo, isto não quer dizer que processo e jurisdição sejam a mesma coisa, nem significa que tenham a mesma meta finalística, especialmente porque são institutos distintos, embora o processo absorva a jurisdição.

Assim, o objetivo do processo não pode ser o mesmo do Poder Jurisdicional. E arrematava - é indiscutível que o fim idealístico e axiológico da jurisdição é a sentença justa. Mas o fim do processo é anterior a essa, ou seja, consiste em ressuscitar a hipótese delitiva (através de depoimentos, acareações, perícias, etc.), fornecendo ao juiz os meios e os elementos necessários para que a jurisdição possa atingir o seu fim último, isto é, a sentença justa.

Se o juiz, que é o titular do Poder Jurisdicional, fosse Deus (que a tudo vê e a tudo ouve), não haveria necessidade de processo, pois aplicaria a sanção justa, tão logo ocorresse o fato delituoso. 
Mas, como o juiz não é Deus nem testemunha (e se o fosse seria ouvido como tal) necessita, primeiro e através do processo, ouvir testemunhas, ordenar perícias e demais diligências, para depois, então, decidir com justiça.

Desta forma, o processo atinge o seu fim, quando o juiz dá início à atividade jurisdicional, elaborando a sentença. É por isso, que somente depois de encerrada a instrução processual e feitas as alegações finais pelas partes, que os autos são conclusos ao juiz para a sentença, isto é, para que a jurisdição atinja o seu ideal com a sentença justa.

\section{Direito de resistência e de rebeldia}

Inobstante esta Casa tenha nascido sob o manto político da filosofia positivista, que pregava submissão à ordem legal, os continuadores e depositários desta tradição cultural souberam consolidar a sua independência de qualquer outra influência que não fosse o livre compromisso com a Ciência do Direito, fazendo jus ao nome com o qual batizaram esta Instituição de "Faculdade Livre de Direito".

E não poderia ser de outra forma, pois o povo gaúcho é o mais politizado deste país, e por isso mesmo não suporta conviver com leis iníquas e muito menos com governos despóticos.

Para tanto, não vamos recordar atitudes pessoais, embora heróicas, como a do consagrado professor
Francisco Brochado da Rocha, que iniciou a revolta vitoriosa de 1930 , tendo sido ferido gravemente.

Nem vamos rememorar, em nível estadual, a bravura dos revolucionários de 1893 e de 1923, na busca de ideais que, a final, foram alcançados, respectivamente, com os Pactos de Pelotas e de Pedras Altas.

Mas vamos sublinhar, isto sim, apenas três fatos nacionais e históricos, que definem a índole libertária desta brava gente que, quando unida em torno das mesmas idéias, sempre venceu a todos os obstáculos:

- a Revolução Farroupilha de 1835, que levou esta Província às últimas consequências, chegando até a proclamação da República do Piratini, cuja pacificação só ocorreu depois de dez anos de luta, com o Tratado do Ponche Verde.

- a Revolução de 1930, que remodelou os costumes e a fisionomia política desta Nação;

- o Movimento da Legalidade de 1961, em respeito à Constituição e à vontade livre e democrática do eleitorado brasileiro.

Pois bem, esse direito de resistência e de rebeldia - pregado por Santo Tomás na Summa Teológica, no século XIII; difundido por John Locke, no século XVII; proclamado pela Declaração dos Direitos do Homem e do Cidadão em 1789 (art. II); valorizado pela melhor doutrina contemporânea; aceito pelas constituições modernas, como a alemã (art.20) e a portuguesa 
(art.21); e, antes de tudo isso, conclamado pela Magna Carta de 15.06.1215, que (revogada por Inocêncio III a 24.08.1215) foi reconquistada, palmo a palmo, em lutas que se seguiram por oito décadas - esse direito de resistência e de rebeldia era um dos temas não só preferidos mas apregoados pelo mestre diante da promulgação de leis injustas, da prepotência dos poderosos e do uso indevido do Poder Público.

Por isso, inspirado em Voltaire e prevenindo o uso do direito de resistência, sintetizava a ação do Estado de Direito nesta mensagem:

É preciso que a ordem juridica amarre as mãos dos governantes para fazer o mal e as deixe livres para realizar o bem.

Como se vê, não há qualquer semelhança com a doutrina inconseqüente do sí hay gobierno soy contra. Não. Aqui há critérios definidos e motivações lícitas e racionais.

Com efeito, quando a lei ou seus agentes atentarem contra as garantias dos cidadãos ou contra os direitos individuais, a resistência e a rebeldia se transformam em deveres dos mesmos cidadãos e indivíduos. Ou, para ser mais preciso ao que foi escrito na Declaração de Direitos (art.II), que resultou da Revolução Francesa:

Quando os governantes violam os direitos do povo, a resistência é para o povo e paracada um em particular, omais sagrado e o mais indispensável dos deveres.
E essa rebeldia, nos seus e nos nossos dias, deve ser traduzida não só pela arma poderosa do voto, mas também pela constante participação em todas as atividades políticas, que circundam as relações humanas na sociedade.

E aqui nesta Faculdade ninguém melhor do que Ney Messias simbolizou a excelência dessa altivez e independência, ou seja, de obediência à lei, enquanto ela for legítima, enquanto atender ao bem comum, enquanto consultar aos interesses maiores do povo.

E lembrando Pontes de Miranda, sublinhava que os atentados à vida e à propriedade eram menos perigosos e prejudiciais ao bem geral do que a menor violência ou coação à liberdade física do indivíduo. Matar um cidadão, confiscar seus bens ou destruí-los, sem acusação e sem processo seria ato de insigne despotismo; mas, a notoriedade do delito levaria ao seio de todo o povo o grito de alarma contra a tirania iminente...

Ao passo que o encarceramento de uma pessoa é arma menos pública e notória, ninguém percebe, ou poucos poderão dela ter notícia. Oprime-se às escuras, nas prisões, no interior dos edifícios, nos porões e nos recantos secretos. É violência silenciosa, invisível, ignorada, secreta e incontrolável. Portanto, mais grave e mais perigosa do que qualquer outra.

Eis porque - acentuava - o primeiro mandamento da cidadania consiste em se ter consciência de que o desrespeito aos direitos de um cidadão representa o desrespeito aos direitos de todos os cidadãos. 
E as notas continuam...

Mas já é hora de encerrar para dar lugar à próxima palestra. Por isso,

- Considerando que o Homem, segundo Aristóteles, é um ser social e político por natureza, e da conscientização dessa vocação depende a sobrevi-vência e a evolução da sociedade;

- Levando em consideração a mesma fonte de sabedoria, que, referindo respeitável corrente filosófica, considera a vida consagrada à política como a única digna do homem;

- Considerando as lições de vida que apreendemos do professor Messias, pela sua palavra e pelo seu exemplo;

- Considerando, ainda, o muito do pouco que dele conhecemos, e tentando interpretar e projetar o seu pensamento, pedimos venia para registrar nos Anais deste Evento Histórico/ Cultural, ao ensejo do Centenário desta Faculdade, uma pequena mensagem dirigida à nossa juventude:

Jovens de todas as idades!

Participem ativamente da política, como ciência e como arte do bem comum, pois só assim se poderá garantir o bem social e individual de cada um; só assim se poderá salvar o nosso País da grave crise em que se encontra, e que é fruto da omissão de muitos, que permitem a poucos desgovernar esta nação, à custa do sofrimento, da insegurança, da miséria e do abandono do povo brasileiro.

Esta é a velha e cada vez mais nova fórmula de cidadania e de resistência, participando incessantemente de todas as atividades relacionadas com o nós, com o eu e com as circunstâncias de cada cidadão.

Assim - no segundo centenário desta Casa - o Brasil será, seguramente, a primeira potência mundial sob as bênçãos do Criador e sob a égide da Democracia, do Direito, da Justiça e da Liberdade. 


\section{$\mathbf{V M +}$}

editoração eletrônica

513222.5044

vmm.ez@terra.com.br

Composto especialmente para a Editora Meridional, em Times New Roman, corpo $11 / 13,9$, sobre o papel offset $75 \mathrm{~g}$ e impresso na

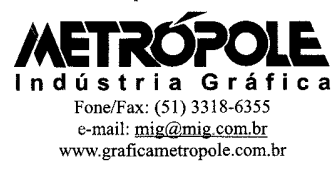




\section{Revista da Faculdade de Direito UFRGS}

Av. João Pessoa, n. 80 - CEP 90.040-000 - Porto Alegre/RS - Brasil

Tel: (51) $3316.3118 / 3316.3128 / 3316.3555 / 3316.3464$

\section{REPRESENTANTES}

ACRE

M.M. Paim Representações e Comércio - F: (68) 224-3432

AMAZONAS

Travessia Editora e Livraria Ltda. - F: (92) 633-6565

Editora Vozes Ltda. 61 - F: (92) 232-5777

BAHIA/SERGIPE

LDM Livraria e Distribuidora Multicampi Ltda. - F: (71) 329-0326

CEARA

Cavalo Marinho Editora Distribuidora e Livraria Ltda. - F: (85) 3223-0321

Livraria Marques Mariano Ltda. - F: (85) 223-4336

DISTRITO FEDERAL

J. Quinderé Distribuidora de Livros Ltda. - F: (61) 347-8461

GOIÁS

Araújo e Dias Ltda. - F: (62) 212-8022

Editora Vozes Ltda. 27 - F: (62) 225-3077

MINAS GERAIS

Alpha Distribuidora de Livros Ltda. - F: (31) 3497-9179

PARA

Ponto e Virgula Comércio Ltda. - (91) 4006-6650

PARAÍBA

Ufpb - Universidade Federal da Paraíba - Casa do Livro - (83) 216-7327

PARANÁ

Livrarias Brooklin Ltda. - F: (41) 3029-3738

PERNAMBUCO

Editora Vozes Ltda. 10 - F: (81) 3423-4100

RIO DE JANEIRO

Prefácio Distribuidora de Livros Ltda. - F: (21) 2508-9797

Susanne Bach Comércio de Livros Ltda. - F: (21) 2539-3590

RIO GRANDE DO NORTE

Potylivros Distribuidora Ltda. - (84) 211-2001

RIO GRANDE DO SUL

Multilivro Distribuidora e Livraria Ltda. - F: (51) 3223-7363

SANTA CATARINA

Livraria Livros \& Livros Ltda. - F: (48) 3028-6244

Unisul - F: (48) 621-3009

Midas Distribuidora e Representações Ltda. - F: (47) 433-0536

SÃO PAULO

Batatais Comércio e Represent. de Livros Ltda. - F: (11) 3266-3097

EDUSP - Editora Universidade de São Paulo - F: (11) 3091-4409

Empório do Livro Ed. e Livraria Ltda. - F: (11) 3255-1447

Lerlivros Distribuidora Ltda. Potyguar - F: (11) 3661-1776

TOCANTINS

S.G.Vieira - Livraria Palmas Cultural - F: (63) 215-3123

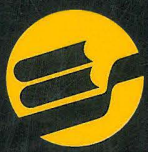

Editora Sulina

www.editorasulina.com.br

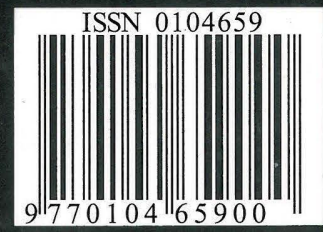

